\title{
PERTUMBUHAN MORFOMETRIK THALLUS RUMPUT LAUT Eucheuma cottonii DI PERAIRAN PULAU BULANG BATAM
}

\section{MORPHOMETRIC GROWTH OF Eucheuma cottoni THALLUS AT BULANG COASTAL AREA}

\author{
Pusvariauwaty Pusvariauwaty ${ }^{1}$, Notowinarto Notowinarto ${ }^{2}{ }^{2}$, Ramses Ramses ${ }^{3}$ \\ ${ }^{1,2,3}$ Program Studi Pendidikan Biologi, FKIP, Universitas Riau Kepulauan, Batam \\ *Koresponden: notowinarto@yahoo.co.id
}

\begin{abstract}
Abstrak
Penelitian bertujuan untuk mengetahui apakah terdapat hubungan pertumbuhan morfometrik thallus rumput laut Eucheuma cottonii dengan kondisi kualitas air yang mempengaruhi pertumbuhan rumput laut. Lokasi penelitian di kawasan perairan Kecamatan Bulang Kota Batam, pada 5 (lima) lokasi yakni perairan; Pulau Balak (ST.I), Kuala Bulang I (ST.II), Pulau Bulang Luar (ST.III), Kuala Bulang II (ST.IV) dan Pulau Mengkada (ST.V). Pengambilan sampel secara purposive sampling sebanyak 6 (enam) kali pengulangan, setiap individu rumpun sampel dilakukan pengukuran morfologi thallus yaitu;panjang thallus (PTI, PTII dan PTIII), diameter thallus III (DTI, DTII dan DTIII) serta bobot massa (BM) dan pengukuran kualitas air. Hasil; panjang dan diameter thallus (PTI, PTII dan PTIII; DTI, DTII dan STIII) memiliki nilai rerata tertinggi didapati pada lokasi ST.I dan ST.V dan terendah pada ST.II, sedangkan pengukuran bobot massa (BM) dengan nilai rerata tertinggi ST.II. Olah analisis sidikragam hubungan antar panjang thallus(PT) dengan berbagai parameter kualitas air (DO, Nitrat/NO3, Phosfat/PO4-P, dan Amonium/NH3-N) pada semua stasiun sampling menunjukan tidak ada hubungan yang signifikan ( Fhit2,97 $<\mathrm{Ftab}_{\mathrm{a}} 4,60$ ), pada diameter thallus (DT) antar stasiun menunjukan tidak nyata ( $\mathrm{F}_{\text {hit }} 1,10<\mathrm{Ft}_{\mathrm{ab}} 4,60$ ), sedangkan hubungan dengan bobot massa (BM) dengan kualitas air antar stasiun menunjukan yakni tidak ada hubungan yang signifikan (Fhit $\left.1,52<\mathrm{Ft}_{\mathrm{ab}} 3,11\right)$.
\end{abstract}

Kata Kunci: Pertumbuhan, Morfometrik Thallus, Kualitas air.

\begin{abstract}
The study aims to determine whether there is a correlation between morphometric growth Eucheuma cottonii seaweed thallus and water quality conditions which influence seaweed growth. The research location was at at 5 (five) location sample at Bulang coastal area, Batam, they are: Balak islet (ST.I), Kuala Bulang I (ST.II), Bulang Luar islet (ST.III), Kuala Bulang II (ST.IV) and Mengkada islet (ST.V). Taking sampling was done by using "Purposive sampling" for six (6) times of repetitions, each individual clumps of sample received thallus morphological measurements namely; long thallus (PTI, PTII and PTIII), diameter thallus III (DTI, DTII and DTIII) and biomass (BM) and water quality measurement. Rresults; thallus length and diameter (PTI, PTII and PTIII; DTI, DTII and ST III) had the highest mean value was found at the location ST.I and ST.V and lowest in ST.II, meanwhile biomass measurement (BM) with a mean value of highest at ST. II. The analysis anova of the correlationp between long thallus $(P T)$ and variety parameters of water quality $\left(\mathrm{DO}\right.$, nitrate $/ \mathrm{NO}_{3}$, Phosfat / $\mathrm{PO}_{4}-\mathrm{P}$ and Ammonium/ $\left./ \mathrm{NH}_{3}-N\right)$ at all sampling stations showed no significant correlation $\left(F_{C o n} 2.97<F_{\text {Tab }} 4.60\right)$, for thallus diameter $(D T)$ among stations showed no real correlation $\left(F_{C o n} 1.10<F_{\text {Tab }} 4.60\right)$, meanwhile the correlation between biomass (BM) and the water quality among stations showed no significant correlation $\left(F_{\text {Con }} 1.52<F_{\text {Tab }} 3.11\right)$.
\end{abstract}

Keywords: Growth, Thallus Morphometrics, Water quality. 


\section{PENDAHULUAN}

Jenis Eucheuma cotonii adalah spesies rumput laut yang banyak dibudidayakan pada beberapa wilayah Kepulauan Riau, yang saat ini terindikasi produktivitasnya cenderung menurun dengan fenomena pertumbuhan lambat, ukuran morfometrik thallus mengecil dan mudah terkena penyakit terutama ice-ice. Hal tersebut diduga karena kondisi kualitas perairan yang relatif menurun akibat perubahan kawasan sepanjang pesisir pantai menjadi zona khusus pengembangan industri perkapalan (shipyard). Karena itu diperlukan kajian untuk mengetahui fenomena permasalahan pertumbuhan rumput laut dengan pendekatan morfometrik dan lingkungan eko-oseanografi.

Rumput laut Eucheuma cotonii tumbuh di rataan terumbu karang dangkal sampai kedalaman 6 (enam) meter, melekat di batu karang, dan benda keras lainnya. Faktor yang sangat berpengaruh pada pertumbuhan jenis ini yaitu cukup arus dan salinitas (kadar garam) stabil. Jenis ini telah di budidayakan dengan cara diikat pada tali sehingga tidak perlu melekat pada substrat karang atau benda lainnya (JanaAnggadiredjo, 2006). Penelitian bertujuan untuk mengetahui apakah ada hubungan pertumbuhan morfometrik thallus rumput laut (Eucheuma cottoni) pada 5 (lima) titik lokasi yaitu Balak, Kuala Bulang I, Bulang Luar, Kuala Bulang II, dan Mengkada dengan kondisi kulitas air secara fisika, biologi, maupun kimiawi yang mempengaruhi pertumbuhan rumput laut tersebut, yaitu akan dilakukan pengukuran secara morfometri meliputi ukuran panjang, berat, serta skala kondisi fisik berdasarkan standar morfologi tubuh tanaman disetiap fase pertumbuhannya sehingga diperoleh informasi untuk determinasi perkembangan menjadi lebih lengkap dan akurat.

\section{METODOLOGI}

Penelitian lapangan dengan pendekatan diskriptif pada populasi rumput laut budidaya sebagai sample diperoleh pada setiap stasiun menggunakan metode purposive sampling. Jumlah cacah sampel 1 - 3 rumpun rumput laut Eucheuma cottonii dari setiap tali (line) penanaman rumput laut tersebut dan dilakukan pengulangan 5-6 kali sampling selama 6 (enam) minggu secara berturut-turut disertai dengan pengambilan data parameter kualitas dari semua stasiun pengamatan, yaitu meliputi; 1) Suhu Permukaan $\left({ }^{\circ} \mathrm{C}\right)$; 2) DHL (mV); 3) Salinitas (ppt); 4) pH; 5) DO (ppm); 6) Nitrat (mg/l); 7) Fosfat (mg/l); 8) Amonia (mg/l); dan 9) Suhu kedalaman (ppm). 
Semua data kemudian dilakukan klarifikasi dan verifikasi serta dimasukkan dalam ringkasan data tabulasi baru. Selanjutnya data tersebut diolah untuk mendapatkan nilai awal yang bersifat umum setiap parameter kondisi kualitas air dari setiap stasiun, yaitu: nilai rerata, nilai tengah dan nilai galat (standar error). Analisis data kemudian dilakukan dengan menggunakan analisis Anova guna mengetahui tingkat hubungan korelasi (r).

\section{PEMBAHASAN}

Secara umum kondisi pertumbuhan morfometrik rumput laut Eucheuma cottonii antar stasiun pengamatan dapat dilihat pada ringkasan tabel antar stasiun berikut ini:

Tabel 1. Ringkasan Rerata Pertumbuhan Morfometrik Rumput Laut Eucheuma cottonii Antar Stasiun Pengamatan

\begin{tabular}{ccccccccc}
\hline \multirow{2}{*}{$\begin{array}{c}\text { Lokasi } \\
\text { Pengamatan }\end{array}$} & \multicolumn{3}{c}{ Panjang Thallus (mm) } & \multicolumn{6}{c}{ Diameter Thallus (mm) } & Berat & $\begin{array}{c}\text { Hijau } \\
\text { Kekuningan }\end{array}$ \\
\cline { 2 - 7 } & PT I & PT II & PT III & DT I & DT II & DT III & (gr) & \% \\
\hline Balak & 1,06 & 1,09 & 0,78 & 0,06 & 0,08 & 0,05 & 1,02 & 87,78 \\
Kuala Bulang & 0,51 & 0,55 & 0,97 & 0,07 & 0,07 & 0,05 & 1,03 & 93,06 \\
$\quad$ I & & & & & & & & \\
Bulang Luar & 0,58 & 0,89 & 0,79 & 0,04 & 0,04 & 0,02 & 1,02 & 85,00 \\
Kuala Bulang & 1,09 & 0,63 & 0,71 & 0,06 & 0,03 & 0,28 & 1,01 & 95,83 \\
$\quad$ II & & & & & & & & \\
Mengkada & 0,90 & 1,53 & 0,52 & 0,04 & 0,04 & 0,05 & 1,01 & 86,67 \\
\hline
\end{tabular}

Tabel 2. Kondisi Parameter Kualitas Air Antar stasiun Pengamatan Di Perairan Kecamatan Bulang

\begin{tabular}{llccccc}
\hline & \multicolumn{5}{c}{ Lokasi Penelitian } \\
\cline { 3 - 7 } No & $\begin{array}{c}\text { Parameter } \\
\text { Kualitas Air }\end{array}$ & $\begin{array}{c}\text { ST. I } \\
\text { Balak }\end{array}$ & $\begin{array}{c}\text { ST. II } \\
\text { Kuala } \\
\text { Bulang I }\end{array}$ & $\begin{array}{c}\text { ST. III } \\
\text { Bulang } \\
\text { Luar }\end{array}$ & $\begin{array}{c}\text { ST.IV } \\
\text { Kuala } \\
\text { Bulang II }\end{array}$ & $\begin{array}{c}\text { ST.V } \\
\text { Mengkada }\end{array}$ \\
\hline 1 & Suhu Permukaan & 29,60 & 29,12 & 30,47 & 29,90 & 29,00 \\
& $\left({ }^{\circ}\right.$ C) & 27,28 & 45,63 & 22,97 & 25,71 & 37,64 \\
2 & DHL (mV) & 29,33 & 21,00 & 26,67 & 22,50 & 27,33 \\
3 & Salinitas (ppt) & 8,18 & 7,34 & 8,79 & 8,26 & 7,30 \\
4 & pH & 5,27 & 8,16 & 7,32 & 6,66 & 6,59 \\
5 & DO (ppm) & 30 & 50 & 70 & 40 & 50 \\
6 & Nitrat (mg/l) & 0,40 & 0,30 & 0,33 & 0,20 & 0,40 \\
7 & Fosfat (mg/l) & 1,17 & 1 & 1,33 & 1,75 & 1,17 \\
8 & Amonia (mg/l) & 32,70 & 31,93 & 33,53 & 32,25 & 31,50 \\
9 & Suhu Kedalaman & & & & & \\
& $\left({ }^{\circ}\right.$ C) & & & &
\end{tabular}


Berdasarkan Tabel 1. beberapa faktor lingkungan yang diukur menunjukan nilai normal yang masih berada pada kisaran kondisi yang cukup baik untuk pertumbuhan morfometrik hal ini dapat dikatakan bahwa pertumbuhan morfometrik rumput laut Eucheuma cottonii yang ada di sekitar kawasan perairan kecamatan Bulang Kota Batam cukup didukung oleh faktor lingkungan. Hasil pengukuran faktor fisika-kimia di kawasan perairan Kecamatan Bulang Kota Batam dapat dilihat pada Tabel 2. Hasil pengukuran seluruh faktor fisika dan kimia budidaya rumput laut Eucheuma cottonii di kawasan perairan Kecamatan Bulang Kota Batam, secara umum masih pada tingkat cukup baik bagi pertumbuhan dan perkembangan budidaya rumput laut.

Alga dapat tumbuh optimal pada pH yang sesuai Supit (1989) menyatakan bahwa hampir seluruh alga menyukai kisaran pH 6,8-9,6. Kondisi ini menggambarkan bahwa $\mathrm{pH}$ di kawasan perairan Kecamatan Bulang Kota Batam masih normal dalam mendukung budidaya rumput laut Eucheuma cottonii. Untuk baku mutu DO untuk rumput laut adalah lebih dari 5 ppm (Sulistijo dan Atmadja, 1996). Iksan (2005) menyatakan perubahan oksigen harian dapat terjadi di laut dan bisa berakibat nyata terhadap produksi alga bentik maupun alge untuk budidaya.

Kondisi ini menggambarkan bahwa DO antar stasiun pengamatan mendukung lokasi pertumbuhan rumput laut Eucheuma cottonii. Pada lokasi Mengkada kandungan Nitrat $\left(\mathrm{NO}_{3}\right)$ berkisar kurang lebih $50 \mathrm{mg} / \mathrm{L}$. maka menurut Baracca, 1999 dalam Iksan, 2005 kondisi perairan tersebut dalam katagori cukup subur yakni mengandung cukup makanan berupa mikro dan makro nutrien. Joshimura (1972) dalam Wardoyo (1978) menyatakan bahwa Nitrat $\left(\mathrm{NO}_{3}\right)$ dalam kodisi berkecukupan biasanya berada pada kisaran minimal antara $30-70 \mathrm{mg} / \mathrm{L}$. Kondisi ini menggambarkan bahwa Nitrat $\left(\mathrm{NO}_{3}\right)$ di kawasan perairan Kecamatan Bulang secara umum masih cukup mendukung pertumbuhan rumput laut Eucheuma cottonii.

Untuk kandungan fosfat, menurut joshimura dalam Wardoyo (1978) bahwa kandungan fosfat yang baik berada pada kisaran 0,10-0,20 mg/L. Kondisi ini menggambarkan bahwa diantara 5 (lima) lokasi pengamatan yang sesuai dengan standart kandungan fosfat yang baik adalah pada lokasi Kuala Bulang II masih layak untuk lokasi budidaya rumput laut Eucheuma cottonii. Hasil analisis sidikragam hubungan korelasi (r ; \%) antara panjang thallus dengan berbagai parameter kualitas air 
(Suhu Permukaan, Salinitas, DO, Nitrat, Fosfat, Amonia) di semua lokasi sampling maka diperoleh olah data yang berhubungan nyata sebagai berikut:

Tabel 3. Rekapitulasi Hubungan ( $\mathrm{r}$; \%) Antara Panjang Thallus Rumput Laut dengan Kondisi Parameter Kualitas Air Penting Antar Stasiun Pengamatan

\begin{tabular}{|c|c|c|c|c|c|c|}
\hline \multirow[b]{2}{*}{ No } & \multirow[b]{2}{*}{$\begin{array}{c}\text { Parameter } \\
\text { Kualitas Air }\end{array}$} & \multicolumn{5}{|c|}{ Lokasi Penelitian } \\
\hline & & $\begin{array}{c}\text { ST. I } \\
\text { Balak } \\
(\%)\end{array}$ & $\begin{array}{c}\text { ST. II } \\
\text { Kuala } \\
\text { Bulang I }(\%)\end{array}$ & $\begin{array}{c}\text { ST. III } \\
\text { Bulang } \\
\text { Luar (\%) }\end{array}$ & $\begin{array}{c}\text { ST.IV } \\
\text { Kuala } \\
\text { Bulang II } \\
(\%)\end{array}$ & $\begin{array}{c}\text { ST.V } \\
\text { Mengkada } \\
(\%)\end{array}$ \\
\hline 1 & $\begin{array}{l}\text { Suhu Permukaan } \\
\left({ }^{\circ} \mathrm{C}\right)\end{array}$ & 70 & 56 & 72 & 73,5 & 66 \\
\hline 3 & Salinitas (ppt) & 78 & 60 & 77 & 82 & 67 \\
\hline 5 & $\mathrm{DO}(\mathrm{ppm})$ & 100 & 98 & 87 & 76 & 88 \\
\hline 6 & Nitrat (mg/l) & 99 & 92 & 90 & 97 & 95 \\
\hline 7 & Fosfat (mg/l) & 99 & 90 & 94 & 90 & 89 \\
\hline 8 & Amonia (mg/l) & 55 & 40,2 & 65 & 46 & 37 \\
\hline \multicolumn{2}{|c|}{ Rerata Korelasi (\%) } & 83,5 & 72,7 & 80,8 & 77,4 & 73,7 \\
\hline
\end{tabular}

Hasil analisis sidikragam hubungan antar panjang thallus dengan berbagai parameter kualitas air (DO, Nitrat $\left(\mathrm{NO}_{3}\right)$, Posfat $\left(\mathrm{PO}_{4}-\mathrm{P}\right)$, dan Amonium $\left.\left(\mathrm{NH}_{3}-\mathrm{N}\right)\right)$ pada semua lokasi sampling maka diperoleh hasil sidik ragam antara panjang thallus dengan kualitas air antar stasiun menunjukan bahwa $\mathrm{F}_{\text {hitung }}(2,97)<\mathrm{Ft}_{\text {abel }}(4,60)$ hal ini dapat disimpulkan hubungan antara panjang thallus rumput laut dengan berbagai parameter kualitas air pada semua lokasi sampling tidak ada hubungan yang signifikan.

Pengukuran analisis sidikragam hubungan antara diameter thallus dengan berbagai parameter kualitas air $\left(\mathrm{DO}, \mathrm{Nitrat} / \mathrm{NO}_{3}\right)$, Posfat $\left(\mathrm{PO}_{4}-\mathrm{P}\right)$, dan Amonium $\left(\mathrm{NH}_{3}\right.$ N) pada semua lokasi sampling diperoleh hasil sidik ragam antara diameter thallus dengan kualitas air antar stasiun menunjukan bahwa $F_{\text {hitung }}(1,10)<\mathrm{Ft}_{\text {abel }}(4,60)$ hal ini dapat disimpulkan hubungan antara diameter thallus rumput laut dengan berbagai parameter kualitas air pada semua lokasi sampling tidak ada hubungan yang signifikan.

Begitu juga pengukuran analisis sidikragam hubungan antara bobot massa dengan berbagai parameter kualitas air (DO, Nitrat $\left(\mathrm{NO}_{3}\right)$, Posfat $\left(\mathrm{PO}_{4}-\mathrm{P}\right)$, dan Amonium $\left(\mathrm{NH}_{3}-\mathrm{N}\right)$ pada semua lokasi sampling diperoleh hasil sidik ragam antara bobot massa dengan kualitas air antar stasiun menunjukan bahwa $F_{\text {hitung }}(1,52)<\mathrm{Ft}_{\text {abel }}$ $(3,11)$ hal ini dapat disimpulkan bahwa antar antara lokasi bobot massa rumput laut tidak dipengaruhi oleh kualitas lingkungan secara umumnya serta tidak ada hubungan yang signifikan antara diameter thallus rumput laut dengan berbagai parameter kualitas air pada semua lokasi sampling. Maka dapat dijelaskan bahwa DO signifikan (berpengaruh). 
Pengaruh DO sangat kuat karena DO termasuk salah satu faktor yang sangat mempengaruhi pertumbuhan rumput laut, serta panjang thallus sangat dipengaruhi DO karena berfungsi dalam proses fotosintesis. Antara panjang thallus dengan Nitrat $\left(\mathrm{NO}_{3}\right)$ signifikan berpengaruh sangat kuat karena Nitrat $\left(\mathrm{NO}_{3}\right)$ termasuk salah satu faktor yang sangat mempengaruhi pertumbuhan rumput laut sebagai sumber makanan. Sedangkan kandungan Fosfat $\left(\mathrm{PO}_{4}-\mathrm{P}\right)$ signifikan sebagai salah satu faktor yang sangat mempengaruhi pertumbuhan rumput laut sebagai sumber makanan.

\section{KESIMPULAN}

Berdasarkan hasil analisis dapat dinyatakan bahwa pertumbuhan thallus rumput laut dengan kondisi kualitas perairan antar stasiun menunjukan adanya hubungan positip atau nyata, tetapi ada indikasi laju pertumbuhan tersebut dipengaruhi oleh fluktuasi kualitas air pada masing-masing stasiun pengamatan. Pertumbuhan thallus dengan kondisi kualitas perairan adalah $\mathrm{DO}$, Nitrat $\left(\mathrm{NO}_{3}\right)$, dan Posfat $\left(\mathrm{PO}_{4}-\mathrm{P}\right)$. DO menunjukan adanya hubungan yang signifikan dengan komunitas di perairan tersebut karena mempengaruhi kesetimbangan kimia air laut dan kehidupan organisme laut.

\section{REFERENSI}

Aslan, L. M., 1998. Budidaya Rumput Laut. Kanisius, Yogyakarta.

Anggadiredja, 2010. Rumput Laut seri Agribisnis. Swadaya, Jakarta.

Ditjenkan Budidaya, 2004. Profil Rumput Laut Indonesia, Jakarta.

Ghufran, 2011. Kiat sukses budidaya Rumput laut di laut \& tambak. Lily Publisher Nybakken, J. W. 1992. Biologi Laut Suatu Pendekatan Ekologi. Gramedia, Jakarta Romimoharto dan Juwana. 2009. Biologi Laut. Djambatan. Jakarta.

Sugiyono, 2011. Statistika untuk penelitian. Alfabeta, Bandung. 